\title{
Vamos de máscara: análise de passo a passo para confecção de máscaras caseiras
}

\author{
Wear a mask: a step-by-step analysis for producing homemade masks \\ Cíntia Raquel Ferreira de Amorim, Eva Rolim Miranda, Solange G. Coutinho
}

design da Informação, artefatos sequenciais, máscaras caseiras, observação direta de utilização

Diante da pandemia da COVID-19, foi necessário integrar em nossa rotina alguns protocolos sanitários, entre eles o uso de máscaras. A presente pesquisa tem como objeto de estudo os passo a passos para confecção de máscaras caseiras em tecido, compreendendo-os como artefatos sequenciais dentro de uma perspectiva de design da informação. O estudo tem como objetivo identificar aspectos problemáticos existentes nos passo a passos e possíveis contribuições do design da informação para melhoria da produção de máscaras caseiras. Para tal, optou-se pela classificações de qualidade com o auxílio do modelo de análise de Sequência Pictórica de Procedimento - SPP de Spinillo (2001), e observação direta do uso dessas instruções com usuários. Os resultados do experimento junto aos participantes mostram a necessidade de aperfeiçoar a disposição das informações, para sanar o problema é apresentado um conjunto de recomendações preliminares, com o aporte do design da informação.

information design, sequential artifacts, homemade masks, task analysis

Due to the COVID-19 pandemic, we have had to introduce certain health protocols into our daily routines, such as, for example, the wearing of masks. Thus, the present study has conducted a step-by-step analysis of how to produce homemade fabric masks, understanding them as sequential artifacts within a perspective of information design. The aim of the study was to identify the problematic aspects that exist throughout the steps, and any possible contributions that information design may offer towards improving the production of homemade masks. To achieve this, we have opted to use quality classifications with the aid of the analytical model of Procedural Pictorial Sequence - PPS proposed by Spinillo (2001) and observing task analysis with the users. The results of the experiment with the participants have demonstrated the need to improve the disposition of the information, to redress the problem, it is presented a group of preliminary recommendations, with input from information design.

\section{Introdução}

No final do ano de 2019 a população mundial foi surpreendida por casos de contaminação do Sars-CoV-2, vírus causador da COVID-19, os primeiros casos da doença foram identificados em Wuhan, na China no mês de dezembro. A Organização Mundial da Saúde declarou o surto de COVID-19 como Emergência de Saúde Pública de Âmbito Internacional em 30 de janeiro de 2020 e uma pandemia, enfrentada por todo planeta, em 11 de março de 2020 (OMS, 2020). Alastrando-se rapidamente o vírus chegou as partes mais extremas continentais, causando

Anais do $10^{\circ} \mathrm{CIDI}$ e $10^{\circ} \mathrm{CONGIC}$

Kelli C.A.S. Smythe, Rafael de Castro Andrade (orgs.)

Sociedade Brasileira de Design da Informação - SBDI

Curitiba | Brasil | 2021
Proceedings of the $10^{\text {th }} \mathrm{CIDI}$ and $10^{\text {th }} \mathrm{CONGIC}$

Kelli C.A.S. Smythe, Rafael de Castro Andrade (orgs.)

Sociedade Brasileira de Design da Informação - SBDI Curitiba | Brazil | 2021 
grande números de mortes, superlotação em hospitais e caos no sistema de saúde de diversos países.

No Brasil, não foi diferente, o número de casos é alarmante e mesmo com algumas medidas de segurança, a exemplo de alguns países aonde a pandemia chegou primeiro, o vírus tem efeito devastador e descontrolado. No início de 2021, foram iniciadas as primeiras iniciativas reais sobre fabricação, distribuição e aplicação de vacinas para contenção do vírus, porém a realidade de uma população completamente vacinada ainda está longe de acontecer. Seja por falta de planejamento e posicionamento frente a aquisição das vacinas ou, de modo geral, por medidas equivocadas na administração pública em prol do combate à pandemia. Ainda assim, mesmo com a aplicação da vacina que ocorre, em sua maioria, em duas doses, alguns cuidados devem ser mantidos.

Ao lidar com um vírus de disseminação acelerada e com fatores ainda pouco conhecidos pela comunidade científica, muitas foram as tentativas de diminuição do contágio, podendo listar: distanciamento social, uso de álcool em gel, higienização das mãos com água e sabão e uso de máscaras faciais de proteção. O uso de máscaras faciais, a princípio, foi recomendado para profissionais de saúde e depois para a população em geral, além disso, o tipo de máscara a ser usado foi alvo de considerações e polêmicas, como também vivências e estudos durante o próprio período pandêmico. Inicialmente as recomendações indicavam apenas o uso de máscaras cirúrgicas, em seguida recomendou-se também o uso de máscaras em tecido, convenientemente chamadas de máscaras caseiras.

A propagação do vírus em escala mundial gerou diversos problemas, inclusive a falta de insumos e materiais preventivos, o uso de máscaras em tecido de algodão para a população em geral, deixando reservado o maior número de máscaras cirúrgicas para os profissionais da área de saúde. A partir dessa demanda, ocorreram inúmeras iniciativas de divulgação de orientações e passo a passo para a produção máscaras caseiras de proteção, que pudessem ser confeccionadas pelos próprios cidadãos. A seguir um exemplo de um passo a passo para confecção de máscara caseira veiculado gratuitamente na internet (figura 1).

Figura 1: Exemplo de passo a passo máscara caseira. (Fonte: https://is.gd/3FzbZ4)

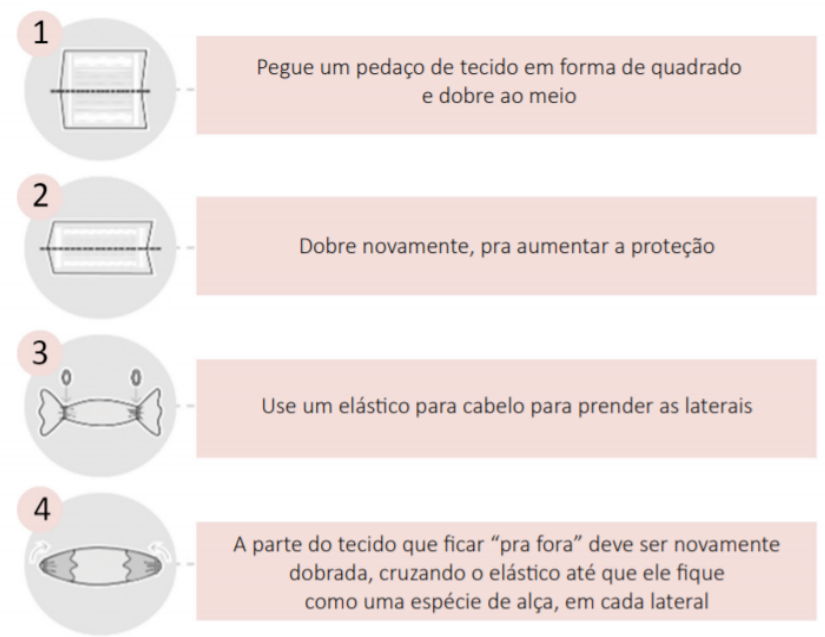


Diversas instruções para produção de máscaras começaram a ser propagados, seja em vídeos, sites, panfletos entre outros. Surgiram inúmeros modelos, com ou sem costura e várias formas de confeccionar. Para esta análise foram selecionados os passo a passos veiculados gratuitamente na internet em formato de imagens digitais e com boa resolução.

Considera-se para este estudo que o uso de desenhos e instruções configurando um passo a passo para a transmissão de informações sobre a confecção de máscaras, como elemento intrínseco à hierarquia e organização informacional. Desta forma, enfatiza-se que o design da informação pode atuar como uma ferramenta democrática com a função de promover e facilitar a absorção, compreensão e uso das informações destinadas a um público (Fujita \& Fontoura, 2005; Redig, 2004). Neste caso, a população com urgência em compreender os elementos essenciais para realizar a confecção de máscaras de proteção, como forma de auxiliar na prevenção de contágio da COVID-19.

No campo do Design da Informação esses passo a passos podem ser considerados Artefatos Sequenciais, pois o encadeamento de imagens em sequência utiliza-se para contar uma história ou transmitir uma informação graficamente (Eisner, 2005). Do ponto de vista da classificação utilizamos para essa pesquisa a proposta de Spinillo (2001) de Sequência Pictórica de Procedimento (SPP). Segundo a autora, a SPP é caracterizada por uma representação procedimental e uma série de passos, apresentada prioritariamente através das ilustrações, de modo a diferenciar do termo instruções visuais configurado como mais abrangentes.

Ainda para a autora, existem quatro grupos para classificar a ordem do estilo com relação a uma SPP: fotográfico, desenho, esquemático e sombra. O grupo estilo de desenho tem como característica a representação que está em uma categoria mediana entre o estilo fotográfico, que possui baixo contraste tonal e alto grau de naturalismo e o esquemático, que possui baixo grau de naturalismo devido à ausência de elementos e grau médio de contraste tonal (Spinillo, 2001). Para a presente análise foram selecionados os passo a passos que tinham estilo de ilustração desenho, visto que foi um dos mais encontrados como resultado nas buscas em meios virtuais.

Desta maneira o objetivo do estudo situou-se em identificar aspectos problemáticos existentes nos passo a passos e as possíveis contribuições da área do design da informação, de forma a aperfeiçoar a organização das informações para confecção de máscaras caseiras.

\section{Metodologia}

O estudo se caracteriza como de caráter analítico, descritivo e qualitativo, visto que a validação qualitativa admite menos importância à quantidade de pessoas da observação e mais ao conteúdo das ações e das respostas ao experimento (Goldenberg, 2015). Além disso, a amostra ocorreu por acessibilidade e conveniência, ou seja, os participantes foram selecionados e convidados por estarem disponíveis para participar do estudo (Gil, 2019, p.106). A realização desta pesquisa consistiu em cinco etapas, a saber: (1) localizar os passo a 
passos online; (2) classificar os passo a passos pelas autoras; (3) classificar os passo a passos por especialistas; (4) classificar e analisar tendo como base as definições das SPPs e, (5) observação direta de participantes durante a utilização dos passo a passos pré-selecionados, para confecção de máscaras caseiras em tecido, como prevenção para a COVID-19 ${ }^{1}$. 0 objetivo foi identificar quais os problemas e, posteriormente, possíveis soluções para a etapa de construção das máscaras, a partir critérios do design da informação.

No primeiro momento, foi conduzida uma busca via internet de acordo com as seguintes palavras-chave: máscara caseira, máscara contra COVID-19, passo a passo e máscara de tecido. Foram encontrados 20 (vinte) passo a passos, dos quais, foram selecionados 12 (doze), com boa resolução da imagem e disponibilização gratuita.

Após esta primeira triagem os passo a passos foram classificados pelas autoras seguindo a uma adaptação da escala Likert (1932) - aqui usada para medir o grau de qualidade dos itens contidos nos passos a passos, na perspectiva do design da informação, de forma negativa ou positiva - de acordo com a variável numérica de 1 a 5, sendo: 1 - ruim, 2 - razoável, 3 - bom, 4 - muito bom, 5 - excelente. Utilizando-se seis critérios: (a) representação gráfica, (b) uso de cores, (c) sequência de tarefas, (d) indicações, (e) presença do texto e (f) divisões ou setas. A fim de validar a classificação das autoras três especialistas (designers gráficos) conduziram as suas classificações, dos mesmos artefatos, por meio de um formulário online via Google Forms. Assim foram selecionados seis passo a passos ranqueados com as melhores pontuações.

Com os seis passo a passos selecionados foi conduzida uma nova classificação, sob a orientação do modelo de análise de Sequência Pictórica de Procedimento - SPP, modelo desenvolvido por Spinillo (2001). Segundo Lopes e Spinillo (2018, p.88) utiliza-se a SPP "como o mais completo para verificar a representação dos passos de uma determinada atividade e/ou ação, por meio da ilustração a fim de fazer um levantamento dos elementos com maior incidência na representação".

Vale destacar ainda que o modelo estabelece a avaliação da análise da tarefa (Spinillo et. al. 2007, 2011; Spinillo \& Waarde, 2011), e, restringe-se a compreensão do seu conteúdo, não avaliando ou descrevendo o estilo de ilustração nesse tipo de documento. O modelo utiliza para análise oito categorias: (a) apresentação de texto, (b) disposição de sequência, (c) orientadores de leitura, (d) elemento de separação visual, (e) elementos simbólicos, (f) elementos enfáticos, (g) estilo de ilustração, (h) representação da figura. Como já mencionado, no nosso estudo adaptamos o sistema de pontuação, usando também a escala Likert para essa etapa, pontuando de 1 a 5: 1 - ruim, 2 - razoável, 3- bom, 4 - muito bom, 5 - excelente, em relação a qualidade do conteúdo. A seguir apresentamos na figura 2 , o esquema representativo da seleção e classificação dos passo a passos deste estudo.

\footnotetext{
${ }^{1}$ O estudo ocorreu entre os meses de novembro de 2020 a março de 2021.
} 
Figura 2: Esquema representativo da seleção dos passo a passos. (Fonte: as autoras)

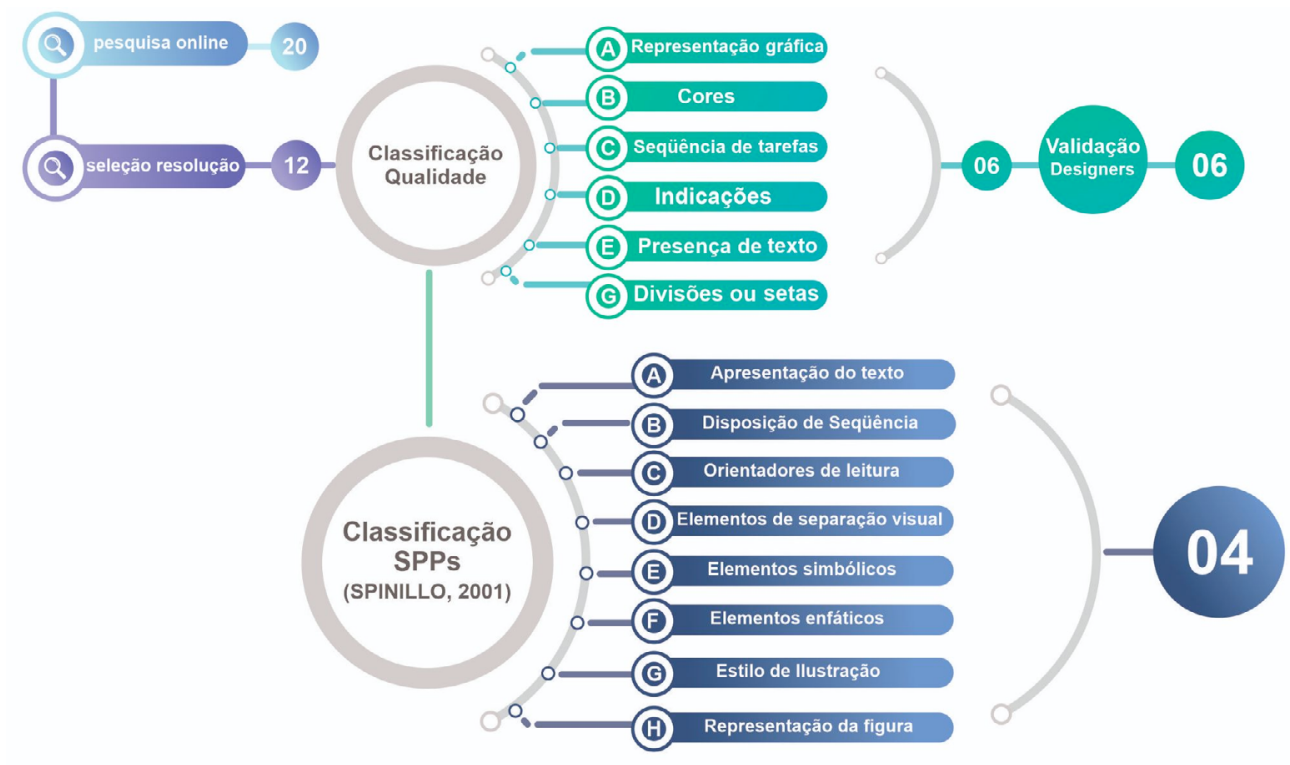

Após a classificação segundo as SPPs foram selecionados quatro passo a passos com maior pontuação, ou seja, os que tiveram análise mais positiva. Dos quatro passo a passos, selecionados, dois tratavam da construção de máscaras sem costura, e dois de máscaras que necessitavam de costura - que poderia ser feita à mão ou à máquina. A seguir os passo a passos selecionados para o experimento com participantes voluntários (figuras 3 e 4):

Figura 3: Passo a passos selecionados para experimento. Grupo 1 (A e C). (Fonte: https://is.gd/sH0n6d https://is.gd/kginoT)

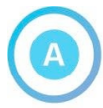

Passo a passo

Como confeccionar seu próprio item de proteçăo

A mais simples

Há diferentes formas de

fazer uma máscara caseira.

(1) Pegue um pedaço de da e dobre no meio.

2 Depois dobre outra vez. para uma maior proteçăb.

(3)

Un elástico de cabelo deve ser colocado em cada lado.

A parte do tecido que ficar para fora" deve ser nova. mente dobrada, cruzando fiasucoco até que ele alça. em cada lateral.

(5)

Essa "alça" será utilizada como suporte na orelha.
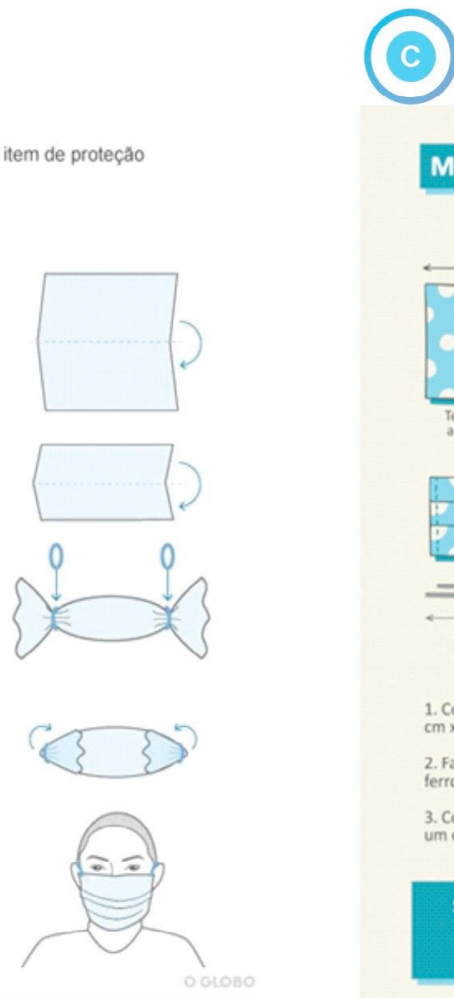

COMO FAZER UMA MÁsCARA de PROTEÇÃo CASEIRA

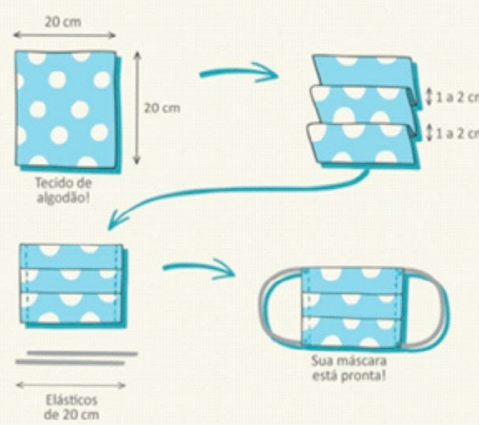

1. Corte um tecido de algodăo em formato de retángulo $(20$ 2. Faça de 2 a 3 dobras, de 1 a $2 \mathrm{~cm}$ cada, e vinque com um ferro de passar;

3. Costure ou cole todas as bordas, sem esquecer de colocar

Se o tecido for fininho, você pode usar até trés camadas de tecido uma sobre a outra para garantir sua proteçăo:) 
Figura 4: Passo a passos selecionados para experimento. Grupo 2 (B e D).

(Fonte: https://is.gd/YCkoLj https://is.gd/7ihYwA)

(B)

Como fazer uma máscara caseira

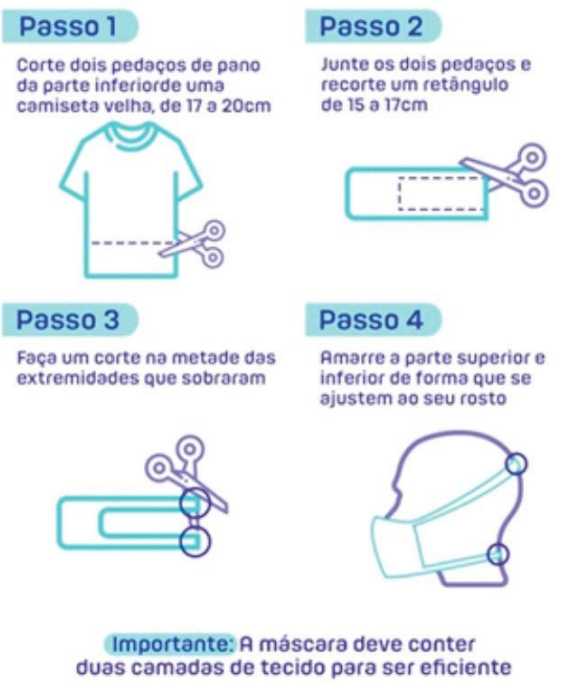

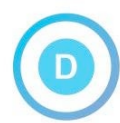
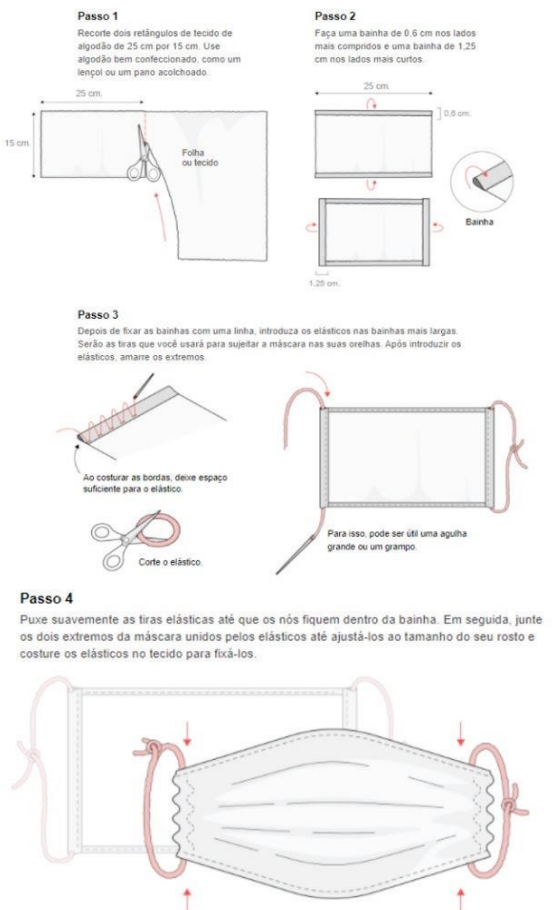

Para participar do experimento foram convidados indivíduos adultos com faixa etária de 25 a 35 anos. Os participantes deveriam realizar a confecção da máscara utilizando o passo a passo, gravar um vídeo do processo de confecção e ao final, preencher um questionário julgando a eficiência da informação, com perguntas relacionadas ao conteúdo presente em cada passo a passo.

A amostragem final contou com dez participantes, que enviaram os vídeos e preencheram o questionário. O grupo foi composto por oito mulheres e dois homens. Sendo seis não especialistas (sem nenhuma experiência em costura) - um homem e cinco mulheres, e quatro especialistas (com experiência básica em costura) - um homem e três mulheres. Divididos em dois grupos identificados por códigos de letras, sendo Grupo 1: três não especialistas - um homem (Z) e duas mulheres (W) $(Y)$ - dois especialistas - um homem (U) e uma mulher (X). No Grupo 2: três não especialistas $(J)(K)(L)$ e dois especialistas $(N)(O)$, cinco mulheres. $O$ Grupo 1 realizou os passo a passos: A (sem costura) e C (com costura) e o Grupo 2 os passo a passos: $B$ (sem costura) e D (com costura). Cada participante realizou dois passo a passos, um sem costura e outro com costura, impreterivelmente. O procedimento teve aplicação semiestruturada, apenas seguindo a sequência dos passo a passos, primeiro sem costura e depois com costura. Sem tempo determinado para cumprir as tarefas. A seguir apresentamos o esquema explicativo dos participantes no procedimento experimental (figura 5). 
Figura 5: Esquema explicativo dos participante no procedimento experimental. (Fonte: as autoras)

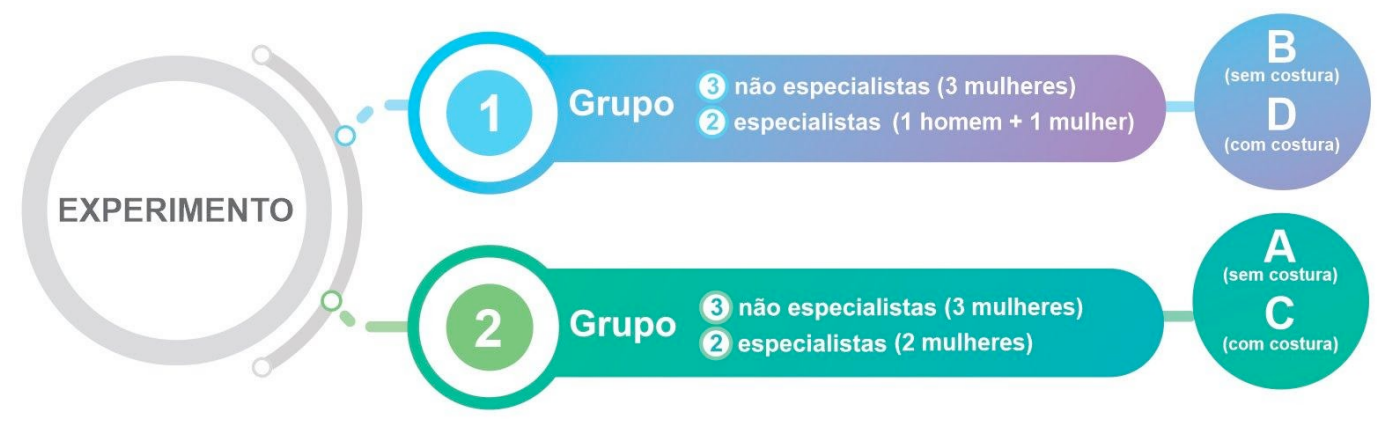

A fase 5 da pesquisa se inicia, com o contato com os participantes por meio de mensagens instantâneas de aplicativo de mensagens (Whatsapp). Antes de realizar o experimento os participantes foram orientados a assinar virtualmente o TCLE (Termo de Consentimento Livre e Esclarecido) por meio de formulário online, via Google Forms, no mesmo link os participantes seriam direcionados para questionário a ser preenchido após a realização das etapas dos passo a passos. No contato prévio via Whatsapp também foram esclarecidas questões referentes à pesquisa e sanadas possíveis dúvidas. A realização dos passo a passos foi filmada pelos próprios participantes e os vídeos enviados posteriormente para as pesquisadoras por Whatsapp ou disponibilizados na nuvem.

No questionário constavam perguntas estruturadas com pontuação de 1 a 5 (1 - ruim, 2 razoável, 3 - bom, 4 - muito bom, 5 - excelente) seguindo a adaptação da escala Likert, mantendo a estrutura já realizada pelas autoras nas análises iniciais (fases 2, 3 e 4). Os critérios eleitos para serem observados pelos participantes levaram em consideração a visão de análise das próprias autoras e o aporte da literatura do modelo de análise de SPP (Spinillo, 2001). Esses critérios foram: (a) disposição do texto, (b) cores, (c) formas dos desenhos, (d) sequência do passo a passo e (e) o espaço entre os desenhos.

O questionário ainda contou com uma questão onde o participante ordenou, do primeiro ao quinto, o grau de contribuição dos elementos contidos no passo a passo, para a confecção da máscara: texto, ilustração, setas, passo a passo e texto + ilustração. Os participantes também emitiram outros comentários sobre a realização dos passo a passos, que foram recebidos via Whatsapp, posteriormente a gravação dos vídeos. Vale ressaltar que as observações orais feitas durante os vídeos, da realização das etapas dos passo a passos, foram também fundamentais para os dados da pesquisa, reforçando o seu caráter descritivo e qualitativo.

\section{Os passo a passos e a informação sequencial}

Em se tratando de design da informação e mais especificamente de artefatos sequenciais, a classificação em termos gerais das aplicações da narrativa sequencial, pode ser subdividida em duas funções: instrução e entretenimento. No caso de artefatos sequenciais de instrução, a exemplo dos passo a passos vislumbrados neste estudo, sua função é de facilitar o entendimento ou explicar a sequência de procedimento de ações necessárias para executar 
uma tarefa, por meio de etapas ilustradas, acompanhadas ou não de textos descritivos, podendo ser técnicos e/ou condicionadores de atitudes (Eisner, 1999).

Ainda sob a ótica das classificações de Eisner (1999) identificamos que os passo a passos que fizeram parte do estudo podem também ser enquadrados no conceito de "quadrinhos condicionadores de atitudes" que têm como características condicionar determinadas atitudes do leitor para executar uma tarefa a partir do processo de imitação. Para Eisner (1999, p. 141) "as pessoas aprendem por imitação, e nesse caso o leitor pode facilmente deduzir, a partir da sua própria experiência, as ações intermediárias ou de conexão". Foi diante dessas perspectivas que foram selecionados os passo a passos de confecções de máscaras faciais, com a intenção de que as pessoas pudessem confeccionar sua própria máscara.

Devido à necessidade de uso imediato e obrigatório de máscaras surgiram grande número de passo a passos compartilhados na internet, o ideal é que toda população tivesse acesso às máscaras de maneira mais rápida possível. Dessa forma entende-se que o cumprimento da atividade de confeccionar a máscara deve ser claro e imediato, a mensagem deve ser compreendida tanto por pessoas que não tem conhecimento em costura, quanto por pessoas que já desenvolveram alguma peça, ou fizeram pequenos ajustes. Assim foram escolhidos passo a passos que poderiam ser feitos sem costura, ou com etapas de costura sem necessidade de aparelhos (máquina de costura), tendo em vista a abrangência do maior número possível de pessoas a confeccionar sua própria máscara. Os passo a passos tinham tanto ilustrações como texto e um número de 4 a 5 etapas de maneira geral.

$O$ desenvolvimento do experimento foi realizado refletindo as características de condicionadores de atitudes, onde o leitor busca executar uma tarefa a partir do processo de imitação, assim os participantes observavam o passo a passo a fim de tentar reproduzir as máscaras. Todos os participantes que fizeram parte da pesquisa enviaram vídeos da realização do experimento, o que foi muito relevante para as análises. Durante os vídeos houve questionamentos, indagações e dificuldades que foram expressas, algumas são destacadas a seguir e também ilustradas na figura 6.

Na confecção da máscara a partir do passo a passo A - Grupo 1 (sem costura), destaca-se que o especialista $(U)$, comentou que entendeu o passo a passo, mas com dificuldade e não recomendaria para outras pessoas. $O$ especialista $(X)$ seguiu a sequência, mas o resultado não ficou igual ao mostrado no desenho final do passo a passo, diante disso afirmou: "Quem vai sair na rua com isso?". Os não especialistas (W) e (Y) também obtiveram como resultado uma máscara diferente do desenho. $O$ não especialista $(Z)$ desistiu de confeccionar a máscara $\mathrm{e}$ afirmou: "Desisto, muito estranho!". Na confecção da máscara a partir do passo a passo C Grupo 1 (com costura), o especialista $(U)$ frisou os elementos de sombra como prejudiciais à compreensão dos desenhos. O especialista $(X)$ criticou a distância do texto e em relação aos desenhos. O não especialista (W) questionou as etapas, ressaltando que não havia explicação de onde se colocaria elástico: "Não diz onde coloca o elástico, fiz por intuição". 
Figura 6: Dificuldades destacadas pelos participantes do Grupo 1 - A e C. (Fonte: as autoras)

\section{Grupo 1}
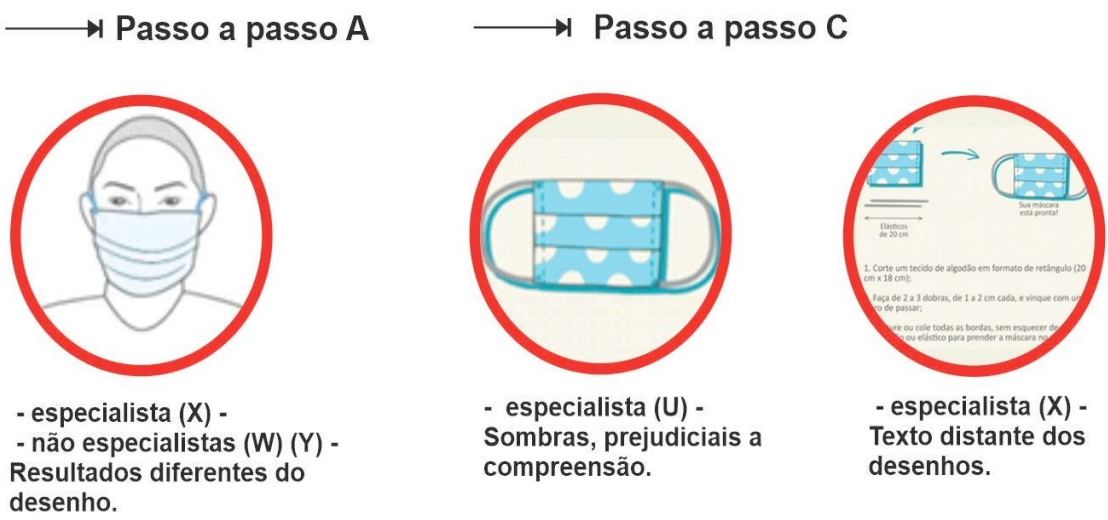

O Grupo 2 confeccionou os passo a passos B e D, na confecção do passo a passo B (sem costura), houve considerações relevantes sobre o resultado obtido, o especialista $(\mathrm{J}$ ) afirmou: "Muito ruim de fazer e resultado feio". O não especialista (M) destacou que não entendeu direito, principalmente a etapa 3 e ainda relatou sobre o resultado: "Muito estranho, minha filha perguntou se eu ia assaltar um banco". O não especialista (L) também afirmou não ter conseguido entender a partir da etapa 2 e desistiu. Durante a confecção do passo a passo $D$ (com costura), pode-se ressaltar que ambos os especialistas $(\mathrm{J})$ e $(\mathrm{K})$ criticaram o formato do desenho da etapa 1, afirmando ser inconsistente. O não especialista $(\mathrm{L})$ também sobre a etapa 1 afirmou: "O desenho desse pano é estranho, confunde demais". E o não especialista (N) ressaltou que o tamanho das letras no passo a passo era pequeno e desproporcional aos desenhos. Os aspectos destacados podem ser vistos nas figuras 7 e 8 .

Figura 7: Dificuldades destacadas pelos participantes do Grupo 2 - D. (Fonte: as autoras)

\section{Grupo 2}

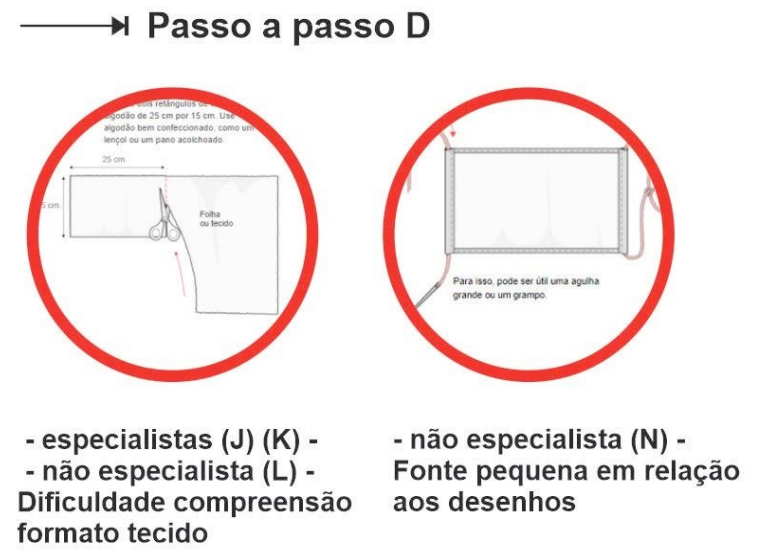


Figura 8: Dificuldades destacadas pelos participantes do Grupo 2 - B. (Fonte: as autoras)

\section{Grupo 2}

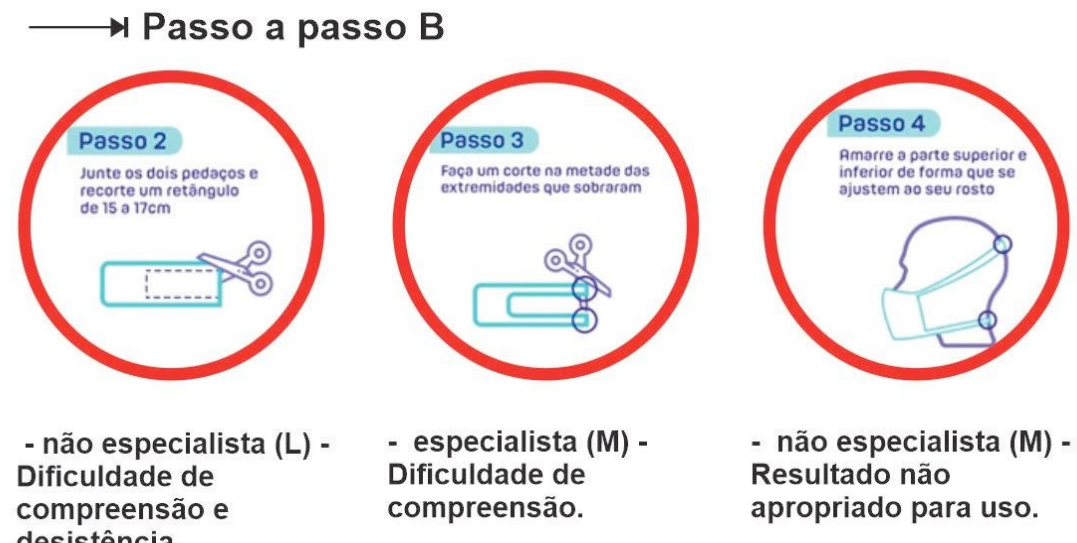

Diante do período de distanciamento social vivido durante a pandemia houve limitações para a aplicação do experimento, visto que as pesquisadoras não puderam acompanhar presencialmente, e em tempo real, as atividades executadas pelos participantes. Eles filmaram os procedimentos e na sequência, nos enviaram os vídeos para análise posterior. Entretanto se manteve contato por WhatsApp, durante cada processo, no caso de dúvidas ou questionamentos.

É importante ressaltar que, embora não houvesse a presença de pesquisadores no local, o experimento tornou-se rico pela espontaneidade das respostas e das reações dos participantes ao lidarem com os passo a passos e tentar confeccionar as máscaras. As falas, indagações e dificuldades registradas nos vídeos, que forneceram os exemplos acima citados, foram essenciais para relacionar as teorias sobre arte sequencial e SPPs, na realização da atividade com os passo a passos selecionados.

\section{As recomendações preliminares}

Diante da literatura utilizada para a primeira fase da pesquisa, e relacionando-a de maneira geral ao experimento, pode-se constatar consonâncias entre a teoria e as observações dos participantes, pois a apresentação da sequência e a disposição do texto mostraram-se relevantes para a facilitação do processo. Os orientadores de leitura, sobressaíram como auxiliares no entendimento da sequência pictórica e os elementos enfáticos tiveram destaque para a importância do seu uso correto, a fim de proporcionar boa visualização dos elementos.

Após as análises dos vídeos, comentários e respostas dos questionários, todos os dados foram compilados e foram desenvolvidas relações dos aspectos problemáticos encontrados nos passo a passos e possíveis melhorias, divididos sob a ótica de cada critério analisado pelos usuários. Assim foram estruturadas recomendações preliminares, de forma a aperfeiçoálos ou até mesmo, ser útil na elaborações de futuros passo a passos de máscaras caseiras em tecido, que possam auxiliar a prevenção ao contágio do COVID-19. 
As recomendações foram baseadas nos dados fornecidos pelas experiências dos usuários, bem como, nas referências da literatura sobre estudos de técnicas de análises de procedimentos (Spinillo, 2001). Já como arcabouço na configuração das recomendações utilizou-se a análise da tarefa, de maneira adaptada, do modelo de avaliação de representações gráficas de análise da tarefa de Padovani e Smythe (2010), com as seguintes categorias: conteúdo (qualidade da informação incluída na representação); estrutura (qualidade da organização dos elementos no espaço); e apresentação (qualidade da linguagem visual aplicada ao texto, imagens, tabelas e uso da cor). Listamos abaixo as dez recomendações na tabela 1.

Tabela 1: Recomendações preliminares desenvolvidas a partir do resultado experimental para produção dos passo a passos para confecção de máscaras faciais caseiras.

\begin{tabular}{|c|c|}
\hline Conteúdo & Recomendações Preliminares \\
\hline Uso de Materiais & $\begin{array}{l}\text { Para o cumprimento de qualquer atividade é imprescindível } \\
\text { que sejam informados os materiais necessários para a } \\
\text { execução. }\end{array}$ \\
\hline Uso de Medidas & $\begin{array}{l}\text { Todas as informações referentes aos tamanhos e medidas } \\
\text { devem estar claras para o cumprimento do passo a passo. }\end{array}$ \\
\hline Uso de sequência & $\begin{array}{l}\text { Determinar uma sequência clara e que contemple todas as } \\
\text { etapas do passo a passo, as sequências podem ser } \\
\text { organizadas de forma horizontal, vertical, oblíqua, ramificada } \\
\text { ou circular, por exemplo. }\end{array}$ \\
\hline $\begin{array}{l}\text { Uso de linguagem } \\
\text { gráfica verbal }\end{array}$ & $\begin{array}{l}\text { Recomenda-se que todas as etapas do passo a passo para } \\
\text { confecção de máscaras devem ter texto de apoio as ilustração. }\end{array}$ \\
\hline \multicolumn{2}{|l|}{ Estrutura } \\
\hline Uso de proporção & $\begin{array}{l}\text { Verificar a proporção entre tamanho das fontes, ilustrações e } \\
\text { imagem para preservar a boa leitura do passo a passo. }\end{array}$ \\
\hline $\begin{array}{r}\text { Uso de } \\
\text { proximidade }\end{array}$ & Usar sempre o texto próximo as imagens e vice-versa. \\
\hline $\begin{array}{r}\text { Uso de } \\
\text { espaçamento }\end{array}$ & $\begin{array}{l}\text { Utilizar um espaçamento proporcional entre o texto e as } \\
\text { ilustrações para compreensão geral do passo a passo. }\end{array}$ \\
\hline \multicolumn{2}{|l|}{ Apresentação } \\
\hline $\begin{array}{l}\text { Uso de elementos } \\
\text { correspondentes }\end{array}$ & $\begin{array}{l}\text { Escolher ou produzir ilustrações correspondentes tanto ao } \\
\text { texto quanto à atividade proposta. }\end{array}$ \\
\hline $\begin{array}{r}\text { Uso de recursos } \\
\text { simbólicos }\end{array}$ & $\begin{array}{l}\text { Usar sempre elementos que possam ajudar na identificação de } \\
\text { atividades, como: corte (linha tracejada), setas (indicação), } \\
\text { entre outros. }\end{array}$ \\
\hline Uso de adornos & Evitar adornos que possam atrapalhar a compreensão. \\
\hline
\end{tabular}

Todas as recomendações têm representatividade de ações que podem ser seguidas para a comunidade em geral, visto que, a própria população pode desenvolver suas próprias 
máscaras e divulgar modos de fazer e passo a passos de diferentes formas, devido à grande demanda e emergencial necessidade de uso.

Por meio dessas recomendações vislumbra-se auxiliar a população a compartilhar a atividade de confecção de suas próprias máscaras. De acordo com o aporte teórico do design da informação e também dos resultados das práticas de usuários compreendidas pelo experimento realizado, no qual, visualizou-se itens problemáticos nos passo a passos estudados, presume-se então, que com o apoio das recomendações esses itens problemáticos podem ser minimizados. $O$ uso das recomendações pode auxiliar na melhoria dos passo a passos já existentes, como também, na criação de futuros passo a passos, que podem ser elaborados de maneira mais eficaz em relação a transmissão de mensagens e por conseguinte a efetivação das etapas para conclusão da atividade.

\section{Considerações Finais}

Importante ressaltar que os 20 (vinte) artefatos selecionados passaram por três processos de escrutínio, antes do experimento com os participantes, quais sejam: (a) foram avaliados pelas pesquisadoras; (b) foram avaliados pelos especialistas; (c) analisados segundo aspectos relevantes das SPPs do modelo de Spinillo (2001). Ou seja, os quatro artefatos finais, foram aqueles escolhidos com o melhor ranking, nas fases anteriores, isso implica que em "tese" eram os que apresentavam pouco ou nenhum problema. Entretanto, não foi o que o experimento com os dez participantes revelou.

A partir das análises dos vídeos e respostas dos questionários, nota-se que a maior parte dos usuários não ficou satisfeito com o resultado das máscaras confeccionadas. Dos dez participantes, três não concluíram pelo menos uma das duas máscaras que teriam que confeccionar. Algumas observações gerais e de destaque foram feitas em relação ao conteúdo geral dos passo a passos, como dificuldade de encontrar as informações, falta de informações de maneira geral, ilustrações incompatíveis com o texto, ou inexistência de ilustrações relativas ao texto, entre outras. Outros participantes insatisfeitos com o resultado, afirmaram que mesmo concluindo as etapas não usariam as máscaras e até mesmo prefeririam comprar, pois o resultado não era satisfatório para uso.

Perante os resultados do experimento e análises realizadas sob a ótica do design da informação, identificou-se a necessidade de contribuição para melhoramento dos passo a passos de confecções de máscaras caseiras.

Diante do exposto, espera-se que as recomendações preliminares indicadas neste trabalho sejam úteis para estudos futuros de forma a auxiliar o melhoramento desses artefatos sequenciais. Visto que, existe uma grande necessidade de uso das máscaras. Como também, vislumbra-se a possibilidade de elaboração de novos passo a passos, seguindo as recomendações preliminares aqui enumeradas, que venham a ser testados para validar os questionamentos levantados nesta pesquisa. 


\section{Referências}

Eisner, W. (1999). Quadrinhos e arte sequencial. São Paulo: Martins Fontes.

Eisner, W. (2005). Narrativas Gráficas. São Paulo: Devir.

Fujita, P. T. L., \& Fontoura, A. M. (2005). O design da informação na Biblioteca Pública do Paraná: aplicação do sense-making e do wayfinding no estudo e análise do espaço informacional. CONGIC 2005. São Paulo: SBDI, 8-16.

Gil, A. C. (2019). Métodos e técnicas de pesquisa social. São Paulo: Atlas.

Goldenberg, M. A (2015). Arte de pesquisar: como fazer pesquisa qualitativa em Ciências Sociais. Rio de Janeiro: Record.

Likert, R. (1932). A technique for the measurement of attitudes. Archives of Psychology, 22(140), 5-55.

Lopes, L.G. A. \& Spinillo, C. G. (2018). Proposta de modelo descritivo para o estilo de ilustração em Sequência Pictórica de Procedimento em bulas de medicamentos. Congresso Internacional de Design da Informação, 8, 4(5), 77-93. https://doi.org/10.5151/cidi2017-008

Padovani, S., \& Smythe, K. C. A. S. (2010). Avaliação de representações gráficas utilizadas em métodos de análise da tarefa. Ação Ergonômica, 5(1),19-26.

https://www.revistaacaoergonomica.org/revista/index.php/ojs/article/view/96

Redig, J. (2010). Não há cidadania sem informação, nem informação sem design. InfoDesign, 1(1), 51-59. https://doi.org/10.51358/id.v1i1.4

Spinillo, C. G., \& Waarde, K. V. (2011). Design de instruções visuais em bulas de medicamentos numa perspectiva internacional: estudo comparativo entre Brasil e Comunidade Europeia. Congresso Internacional de Design da Informação, 5, 113-119.

Spinillo, C. G., Souza, J. M. B., Storck, G. R., \& Pottes, A. (2011). Aspectos sobre os modos de representação e o processamento da informação em instruções visuais animadas. Anais do 110 ERGODESIGN/USIHC. Manaus: UFM, v.1, 15-26.

Spinillo, C. G., Padovani, S., Miranda, F., \& Fujita, P. T. L. (2007). Instruções visuais em bulas de medicamentos no Brasil: um estudo analítico sobre a representação pictórica da informação. Congresso Internacional de Design da Informação, 3, 1CD-ROM.

Spinillo, C. G. (2001). Instruções visuais: algumas considerações e diretrizes para sequencias pictóricas de procedimentos. Estudos em Design. 9 (3), 31-50.

OMS, Organização Mundial de Saúde; OPAS, Organização Pan-Americana de Saúde (2020). OMS afirma que COVID-19 é agora caracterizada como pandemia. Disponível em https://www.paho.org/bra/index.php?option=com_content\&view=article\&id=6120:omsafirma-que-covid-19-e-agora-caracterizada-como-pandemia\&ltemid $=812$

\section{Sobre as autoras}

Cíntia Raquel Ferreira de Amorim, Mestra, UFPE, Brasil <cintia.r.amorim@gmail.com>

Eva Rolim Miranda, Doutora, UFAL, Brasil <eva.miranda@fau.ufal.br>

Solange Galvão Coutinho, PhD, UFPE, Brasil <solange.coutinho@ufpe.br> 